\title{
Long-Term Outcomes of Gastric Endoscopic Submucosal Dissection: Focus on Metachronous and Non-Curative Resection Management
}

\author{
D. Libânio ${ }^{a, b}$ P.Pimentel-Nunes ${ }^{a, b}$ L.P. Afonso ${ }^{c}$ R. Henrique ${ }^{c}$ \\ M. Dinis-Ribeiro ${ }^{a, b}$ \\ ${ }^{a}$ CINTESIS - Center for Health Technology and Services Research, Faculty of Medicine, University of Porto, and \\ ${ }^{b}$ Gastroenterology Department and ${ }^{C}$ Pathology Department, Portuguese Institute of Oncology of Porto \\ (IPO-Porto), Porto, Portugal
}

Keywords

Gastrointestinal endoscopy · Gastric mucosa · Risk factors ·

Stomach neoplasms · Treatment outcome

\section{Abstract}

Introduction: Endoscopic submucosal dissection (ESD) is an effective treatment for gastric superficial neoplasms and curative in $80-85 \%$ of the patients. The aims of this study were to identify risk factors for non-curative resection and metachronous development, and to evaluate patient management and outcome after non-curative resection. Methods: In this single-centre study, the outcome of consecutive patients submitted to gastric ESD was assessed during a minimum follow-up of 18 months. Univariate analysis and multivariate logistic regression were performed to identify risk factors. Results: ESD was performed in 194 lesions (164 patients) between 2005 and 2014. The median follow-up was 40 months. En bloc and complete resection rates were 95.3 and $93.8 \%$, respectively. Male sex, larger tumor size,

\section{KARGER}

E-Mail karger@karger.com www.karger.com/pjg
(C) 2016 Sociedade Portuguesa de Gastrenterologia Published by S. Karger AG, Basel Karcer Open access

This article is licensed under the Creative Commons AttributionNonCommercial-NoDerivatives 4.0 International License (CC BYNC-ND) (http://www.karger.com/Services/OpenAccessLicense) Usage and distribution for commercial purposes as well as any distribution of modified material requires written permission. longer procedural time, and more advanced histology were associated with a non-curative resection $(p<0.05)$, but only carcinoma detected in biopsies before resection was identified as a significant risk factor on multivariate analysis. Metachronous lesions occurred in $18.4 \%$, and the incidence rate was 4.7 lesions/100 person-years. Older age at diagnosis was identified as the only predictor of metachronous development in logistic regression. In the non-curative resection group, survival did not differ between patients allocated to surveillance and those submitted to gastrectomy; $75 \%$ of gastrectomy specimens showed no residual lesion. Conclusions: The risk factors identified for non-curative resection help to improve patient selection and patient information. Older patients had an increased risk for the development of metachronous lesions. In patients with non-curative resections, individualized patient management and surveillance seems to be an adequate option in selected cases.

(c) 2016 Sociedade Portuguesa de Gastrenterologia Published by S. Karger AG, Basel 
Resultados a Longo Prazo da Disseção Endoscópica da Submucosa Gástrica: Foco nas Lesões Metácronas e na Abordagem da Resseção Não Curativa

\section{Palavras Chave}

Endoscopia gastrointestinal - Factores de Risco . Mucosa gástrica · Neoplasias gástricas · Resultado do Tratamento

\section{Resumo}

Introdução: A disseção endoscópica da submucosa (ESD) é um tratamento eficaz nas neoplasias gástricas precoces, sendo curativa em $80-85 \%$. Os objetivos deste estudo foram identificar fatores de risco para resseção não curativa e para o desenvolvimento de lesões metácronas, bem como avaliar a abordagem e os resultados após resseção não curativa. Métodos: Estudo de coorte, unicêntrico, incluindo doentes consecutivos submetidos a ESD gástrica com tempo mínimo de follow-up de 18 meses. Análise univariada e multivariada utilizadas na identificação de fatores de risco. Resultados: Entre 2005 e 2014, 194 lesões (164 doentes) foram submetidas a ESD (tempo mediano de follow-up 40 meses). Resseções em bloco e completa: 95.3 e $93.8 \%$. Sexo masculino, lesão maior, procedimento demorado e histologia mais avançada associaram-se a resseção não curativa $(p<0.05)$; na análise multivariada, adenocarcinoma nas biopsias foi identificado como fator preditor. Ocorreram lesões metácronas em 18.4\% (taxa de incidência 4.7/100 pessoas-ano), sendo a idade mais avançada fator de risco independente para lesões metácronas. Nos casos de resseção não curativa, a sobrevivência foi semelhante nos doentes alocados para vigilância e nos submetidos a gastrectomia; em $75 \%$ não havia doença residual na peça cirúrgica. Conclusões: Os fatores de risco identificados são úteis na seleção apropriada dos doentes e na transmissão da informação. A incidência de lesões metácronas é significativa, estando os doentes mais velhos em maior risco. Após resseção não curativa a decisão deve ser individualizada, sendo a vigilância apropriada em casos selecionados.

(0) 2016 Sociedade Portuguesa de Gastrenterologia Publicado por S. Karger AG, Basel

\section{Introduction and Aims}

Gastric cancer is a major health problem, being the 5th most common cancer and the 3 rd cause of cancer-related death [1]. Portugal is a country with a high/moderate incidence of gastric cancer [2], and the burden of digestive diseases increased in the past decade [3].

The increasing availability of upper digestive endoscopy, together with surveillance of patients with precancerous conditions [4], improves the detection rate of early neoplastic lesions that can be successfully treated with endoscopic resection, e.g., endoscopic submucosal dissection (ESD) or endoscopic mucosal resection.

Indeed, endoscopic resection is a minimally invasive treatment that has been shown to have a high efficacy in selected patients, with a better safety profile and a better quality of life than surgery [5-7]. Nevertheless, some disadvantages are also associated with endoscopic treatment. Namely, endoscopic resection is curative in 80 $85 \%$ of the cases, meaning that $15-20 \%$ of the patients that are submitted to endoscopic resection will need to undergo gastrectomy with lymphadenectomy. Thus, the identification of risk factors for a non-curative resection is of paramount importance to improve patient selection. Additionally, patients with an early neoplastic lesion are at risk of developing metachronous lesions, and endoscopic surveillance is still required after endoscopic resection. The identification of risk factors for metachronous lesion development is also important to adapt surveillance to individual patients and to answer unsolved questions, such as when to stop surveillance. Furthermore, as $15-20 \%$ of the resections are considered non-curative, it is important to adapt patient management after an unsuccessful treatment in order to assess the clinical outcomes of available options (careful surveillance or surgical treatment).

The main aim of this study was to evaluate long-term outcomes of endoscopic resection, with special attention to management strategies after a non-curative resection. Secondary aims were to identify risk factors for a noncurative resection and for the development of metachronous lesions over time.

\section{Patients and Methods}

\section{Study Design, Setting, and Participants}

This was a single-centre assessment of a cohort of consecutive patients with gastric superficial neoplasms submitted to ESD in IPO-Porto between October 2005 and July 2014 (retrospective assessment of prospectively collected data). Patients were included 
if there was an adequate follow-up (at least 18 months or until death) and excluded from analysis if resection was considered non-feasible (procedure interruption due to technical difficulties).

Patients were provided information about the benefits and risks of endoscopic resection, and when there was doubt about the best treatment method, patients were evaluated by a multidisciplinary team including gastroenterologists, oncologists, and surgeons; the patient's opinion was also part of the decision-making process.

Gastric ESD was performed by 2 operators (M.D.-R. and P.P.-N.) who had adequate training in this technique (animal models and supervised human training). Endoscopic evaluation and determination of margins was performed with chromoendoscopy with $0.5 \%$ indigo carmine, which was replaced by virtual chromoendoscopy with Narrow Band Imaging (Olympus ${ }^{\circledR}$ ) after 2012. Small coagulation marks were made around the lesion $(2-5 \mathrm{~mm}$ outside), and then submucosal injection was performed with saline, diluted epinephrine (1:100,000), and methylene blue. After elevation, 3-4 incisions were made with a needle knife (mainly Hook$\mathrm{Knife}^{\mathrm{TM}}$; Olympus ${ }^{\circledR}$ ) to get access to the submucosal layer, and an insulated-tip knife (mainly IT-Knife ${ }^{\mathrm{TM}}$; Olympus ${ }^{\circledR}$ ) was used to perform circumferential dissection using the Endo Cut mode (Olympus electrosurgical unit, 80/60 W). Complete dissection was then performed in the Endo Cut mode, with additional submucosal injection whenever necessary. The procedures were performed mainly under general anaesthesia (with orotracheal intubation); deep sedation was restricted to a minority of procedures.

Patients received esomeprazol ( $80 \mathrm{mg}$ ), a proton pump inhibitor, as an intravenous bolus in the morning of the procedure and as a continuous intravenous infusion $(8 \mathrm{mg} / \mathrm{h}$ for $48-72 \mathrm{~h}$ ) after the procedure. Patients were given a liquid diet $24 \mathrm{~h}$ after the procedure and a soft diet after $48 \mathrm{~h}$. In the absence of complications, patients were normally discharged $48-72 \mathrm{~h}$ after the procedure and instructed to take a proton pump inhibitor twice a day for 14 days and then a single dose until the next appointment, which was scheduled 4-8 weeks after discharge to discuss the histopathological results and to establish if additional treatment or endoscopic surveillance is needed.

When the resection met curative criteria, patients were included in an endoscopic surveillance program (with the first endoscopy being performed 3 months after ESD, the second 9 months after ESD, and yearly thereafter). Chromoendoscopy (conventional or electronic) was performed, and scar biopsies were collected if there was endoscopic suspicion of recurrence. Radiological surveillance in case of expanded criterion resections was performed at the discretion of the assistant physician. In patients with noncurative resection allocated for endoscopic surveillance (local-risk resections or high-risk resections in patients not fit for surgery or who refused surgery), scar biopsies were routinely performed. Helicobacter pylori eradication was also proposed to patients with curative resections.

Written informed consent was obtained from all patients. This study was conducted in accord with the ethical principles of the Declaration of Helsinki.

\section{Definition of Variables}

Data collection included clinical and demographic variables such as age, gender, ASA status (American Society of Anaesthesiologists' classification of Physical Health), comorbidities and antithrombotic medication. Lesions were classified according to their size (endoscopic assessment and pathological measurements), morphology (according to the Paris classification [8]), presence of ulceration, and localization (upper, middle , or lower third of the stomach). Subsequently, lesions were classified into polypoid ( 0 Is, 0-Ip, or 0-Isp), non-polypoid, non-depressed (0-IIa, 0-IIa+b, or $0-$ IIb), and depressed (0-IIc component or 0-III). Synchronous lesions were divided into accessory lesions (less advanced lesions removed together with the main lesion) and synchronous lesions detected at the first follow-up. A lesion was considered metachronous when it was detected after the first endoscopic follow-up (i.e. at the second follow-up examination or later) in a different localization from the index lesion. Histological upgrade was considered when the histopathological evaluation of the resected specimen revealed a more advanced histology than the biopsies before resection.

Two pathologists with experience in gastrointestinal pathology performed the histopathological evaluation of the resected specimens, and the final diagnosis was made according to the SydneyVienna classification [9].

A complete resection (R0) was defined as an en bloc resection with free endoscopic and histological margins. Recurrence was defined as the appearance of a neoplastic lesion clearly at the site of the previous ESD. For risk stratification, the Japanese Classification of Gastric Cancer was used in routine clinical practice [10]. A curative resection was considered when the following criteria were met in a lesion completely resected, and when there was no lymphovascular or perineural invasion:

1 dysplastic lesion of any size (standard criteria)

2 intramucosal, $\leq 20 \mathrm{~mm}$, well/moderately differentiated carcinoma without ulcerative findings (standard criteria)

3 intramucosal, well/moderately differentiated carcinoma of any size without ulcerative findings (expanded criteria)

4 intramucosal, well/moderately differentiated carcinoma with ulcerative findings, $\leq 30 \mathrm{~mm}$ (expanded criteria)

5 well/moderately differentiated carcinoma, $\leq 30 \mathrm{~mm}$, without ulcerative findings but with minute submucosal invasion $(<500$ $\mu \mathrm{m})$ (expanded criteria)

6 poorly differentiated intramucosal carcinoma, $\leq 20 \mathrm{~mm}$, without ulcerative findings (expanded criteria).

Additionally, a retrospective classification according to the recently published guidelines of the ESGE (European Society of Gastrointestinal Endoscopy) was also performed [11].

Patients with lesions not meeting criteria for curative resection were then evaluated in a multidisciplinary team that decided the approach according to the patients' clinical condition, taking the patient's opinion and histopathological results into account.

\section{Statistical Analysis}

Descriptive statistics were analyzed for each collected variable (means and SD for normally distributed continuous variables and medians and interquartile ranges when the distribution was not normal; frequencies and percentages for categorical variables). Continuous variables were compared between groups with independent samples $t$ test or Mann-Whitney $U$ test; for categorical variables, the $\chi^{2}$ test or Fisher exact test were used. Multivariate logistic regression models were constructed to identify significant predictors of noncurative resection and for metachronous lesion occurrence. Odds ratios (OR) were computed along with 95\% confidence intervals (95\% CI). Survival was analyzed using Kaplan-Meier curves and the log-rank test. Significance was defined as $p \leq 0.05$. 
Table 1. Risk factors for non-curative resection

\begin{tabular}{|c|c|c|c|c|c|}
\hline & $\begin{array}{l}\text { Non- } \\
\text { curative }\end{array}$ & Curative & $\begin{array}{l}p \\
\text { value }\end{array}$ & $\begin{array}{l}\text { OR } \\
(95 \% \mathrm{CI})\end{array}$ & $\begin{array}{l}\text { Adjusted OR } \\
(95 \% \mathrm{CI})\end{array}$ \\
\hline Age, years & $70.5 \pm 9.1$ & $68.47 \pm 10.7$ & 0.329 & & $1.01(0.97-1.05)$ \\
\hline \multicolumn{6}{|l|}{ Gender } \\
\hline Males & $21(20.2)$ & $83(79.8)$ & 0.050 & $1.38(1.05-1.83)$ & $2.01(0.84-4.81)$ \\
\hline Females & $9(10)$ & $81(90)$ & & 1 & 1 \\
\hline \multicolumn{6}{|l|}{ ASA status } \\
\hline ASA III/IV & $9(23.1)$ & $30(76.9)$ & 0.141 & $1.64(0.87-3.09)$ & \\
\hline Median (SD) tumor size , mm & $26.1(8.9)$ & $19.9(7.8)$ & 0.001 & & \\
\hline \multicolumn{6}{|l|}{ Tumor size } \\
\hline$<20 \mathrm{~mm}$ & $6(8.1)$ & $68(91.9)$ & & 1 & 1 \\
\hline$\geq 20 \mathrm{~mm}$ & $24(20)$ & $96(80)$ & 0.026 & $2.83(1.09-7.30)$ & $2.43(0.91-6.54)$ \\
\hline Procedure time, $\min$ & $104.7 \pm 44.6$ & $91.7 \pm 58.7$ & 0.031 & & \\
\hline \multicolumn{6}{|l|}{ Morphology } \\
\hline Polypoid & $4(23.5)$ & $13(76.5)$ & & $1.69(0.47-6.1)$ & \\
\hline Non-polypoid, non-depressed & $12(15.4)$ & $66(84.6)$ & 0.613 & 1 & \\
\hline Depressed & $14(14.1)$ & $85(85.9)$ & & $0.91(0.39-2.1)$ & \\
\hline \multicolumn{6}{|l|}{ Biopsies before resection } \\
\hline Low-grade dysplasia & $6(9.7)$ & $56(90.3)$ & & 1 & 1 \\
\hline High-grade dysplasia $^{a}$ & $11(12.8)$ & $75(87.2)$ & 0.038 & $1.37(0.48-3.92)$ & $1.06(0.36-3.14)$ \\
\hline Carcinoma $^{a}$ & $13(28.9)$ & $32(71.1)$ & & $3.79(1.31-10.95)$ & $3.04(1.02-9.06)$ \\
\hline
\end{tabular}

Means \pm SD or $n(\%)$ unless stated otherwise. ${ }^{\text {a }}$ OR for carcinoma (vs. high-grade dysplasia) $=2.77(1.12-6.83)$.

In the analysis of short-term outcomes and risk factors for curative resection, a per lesion analysis was performed. A per patient analysis considering the moment from the first ESD was preferred when analyzing long-term outcomes (namely survival) and the incidence and risk factors for metachronous lesions.

\section{Results}

During the study period, 164 patients (194 lesions) were submitted to ESD. ESD was not feasible in 6 additional patients that were scheduled for the procedure $(5$ due to inadequate elevation and 1 due to the occurrence of an uncontrolled intraoperative bleeding that needed surgery).

\section{Short-Term Outcomes and Risk Factors for}

Non-Curative Resection

En bloc and complete resection was performed in 95.3 and $93.8 \%$, respectively. Overall adverse events oc- curred in $13 \%$; bleeding occurred in $8 \%$, and muscular wall laceration or perforation in 3\%. All adverse events were managed conservatively except in 1 patient with uncontrolled postoperative bleeding that required surgery.

Clinical, endoscopic, and pathological characteristics of the 194 ESD lesions are presented in Table 1 combined with the analysis of risk factors for non-curative resection. In univariate analysis, male sex, tumor size $\geq 20 \mathrm{~mm}$, longer procedure time, and more advanced histology in biopsies before resection were associated with non-curative resection, although when adjusting for other factors (age, sex, tumor size, localization, and morphology) only carcinoma in biopsies was identified as an independent predictor of non-curative resection (adjusted OR 3.04, 95\% CI 1.02-9.06). Tumor localization and morphology were not found to significantly influence the likelihood of a curative resection, although resection of polypoid lesions was non-curative in $23.5 \%$. Piecemeal resection was associated with non-curative resection, although accord- 
Table 2. Risk stratification according to ESGE guidelines

\begin{tabular}{lll}
\hline Risk stratification & $n(\%)$ & Criteria \\
\hline Low-risk resection & $164(84.5)$ & 126 standard criteria \\
& & 38 expanded criteria \\
Local-risk resection & $11(5.7)$ & en bloc HM1/HMx dysplasia \\
& & 5 en bloc HM1/HMx carcinoma \\
& 5 piecemeal $(3$ dysplasias, 2 carcinomas $)$ \\
& 12 submucosal invasion $\geq 500 \mu \mathrm{m}$ in a lesion $\geq 30 \mathrm{~mm}$ \\
High-risk resection $^{\mathrm{a}}$ & $19(9.8)$ & 10 lymphovascular invasion \\
& & 4 poor differentiation and 2 mixed type $\geq 20 \mathrm{~mm}$ \\
& & 4 positive vertical margins
\end{tabular}

a One criterion in 9; 2 criteria in 6; 3 criteria in $4 . \mathrm{HM} 1 / \mathrm{HMx}$, positive/indeterminate horizontal margins.

ing to the ESGE guidelines a majority of these cases corresponded to local-risk resections due to indeterminate margins and were managed with endoscopic surveillance with additional treatments when necessary.

Histological upgrade (from low- to high-grade dysplasia or from high-grade dysplasia to carcinoma) occurred in $49.5 \%$ of the cases, with upgrade from dysplasia (low or high grade) to carcinoma being found in $31.4 \%$.

\section{Long-Term Outcomes}

Table 2 summarizes risk stratification according to the ESGE guidelines. In 135 patients, the initial resection was considered curative (low-risk resection). There were 24 metachronous lesions in 21 patients (15.6\%), with 19 being successfully treated with endoscopic resection. Two metachronous lesions were considered not suitable to endoscopic resection and were further treated with surgery, while 2 patients underwent non-curative ESD. Both patients refused surgery after discussion and no loco-regional or distant recurrence was found during follow-up (5 and 1.5 years). One patient with a metachronous dysplastic lesion refused any additional treatment.

\section{Management and Clinical Outcomes after \\ Non-Curative Resection}

The most common reason for considering a resection as a local-risk resection was indeterminate or positive horizontal margins (Table 2). Patients with high-risk resections frequently had more than 1 unfavourable prognostic criterion (mainly deep submucosal invasion and/ or lymphovascular permeation).

In per-patient analysis, the first ESD was non-curative in 28 (10 local-risk resections and 18 high-risk re- sections according to the ESGE guidelines). Local-risk resections were managed with careful endoscopic surveillance (and radiologically where adequate, i.e. in cases with carcinoma in the histopathological specimen) in 9 patients; there was 1 metachronous lesion and 1 recurrence, both successfully treated with ESD. In the 18 high-risk resections, 12 underwent surgery while careful follow-up was decided in 6 patients. In the surveillance group, 2 patients had local recurrence that was successfully treated with endoscopic resection while 1 patient that refused surgery developed distant metastasis after 3 years and died of gastric cancer. There were 2 metachronous lesions in the same patients that had local recurrence, both treated with ESD. After gastrectomy, no residual disease was found in the gastrectomy specimen in $75 \%$. There was nodal involvement in only 1 patient (with submucosal invasion $\geq 500 \mu \mathrm{m}$ and lymphovascular invasion), while 2 had residual neoplasia in the gastric wall (corresponding to cases of piecemeal/ $\mathrm{R} 1$ resection). Complications of gastrectomy occurred in 2 patients (16.7\%). Of the patients submitted to gastrectomy, 1 died due to dehiscence and peritonitis, while 2 died 2 months after surgery due to comorbidity decompensation.

\section{Metachronous Lesions - Incidence and Risk Factors}

Globally, metachronous lesions occurred in $14.7 \%$. When considering only patients allocated to endoscopic surveillance, the cumulative incidence was $18.4 \%$ (Fig. 1); 3 patients had $\geq 2$ lesions. Metachronous lesions were detected at a median time of 24 months (interquartile range 9-50.25) and the incidence rate was 4.7/100 person-years. Older age at diagnosis ( 72.3 vs. 67.6 years) and male sex 


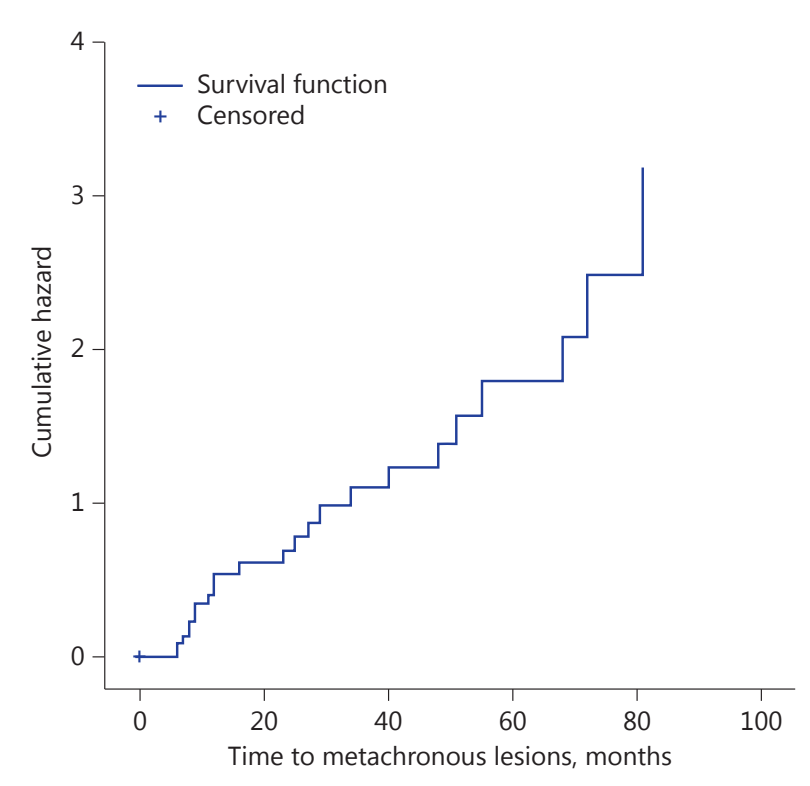

Fig. 1. Metachronous lesions occurred in $18.4 \%$ of the patients allocated for surveillance (incidence rate 4.7 lesions/100 personyears).

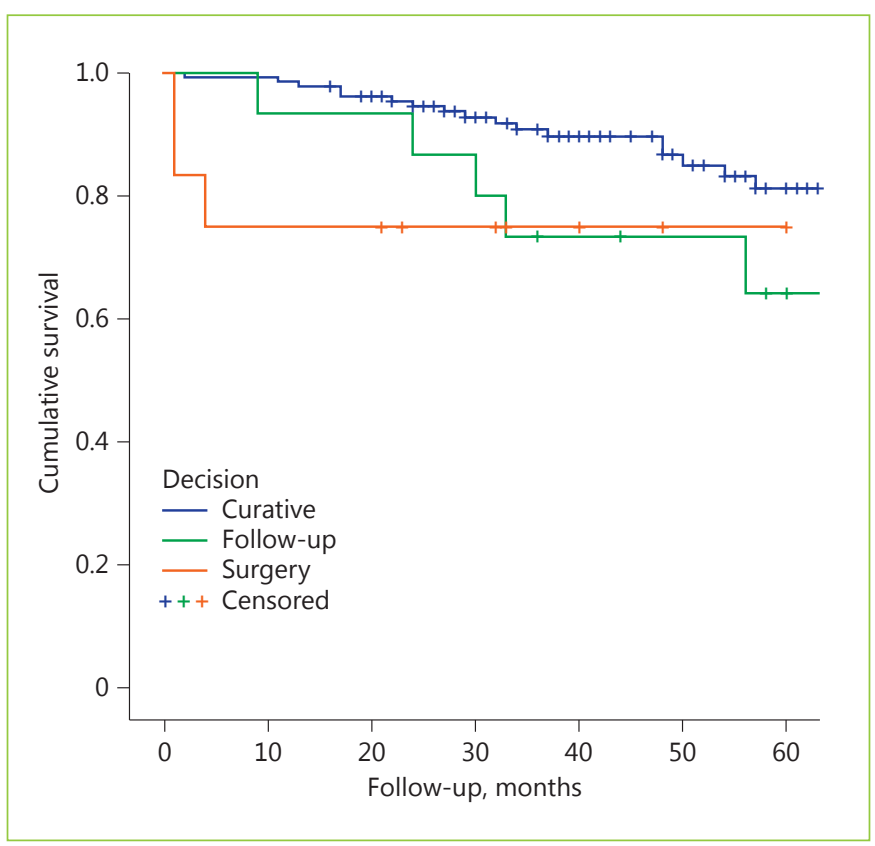

Fig. 2. Overall survival was similar in patients submitted to surgery and patients followed up (log-rank test $0.009, p=0.929$ ), although patients with non-curative resections had significantly lower survival (log-rank test 4.538, $p=0.033$ ).

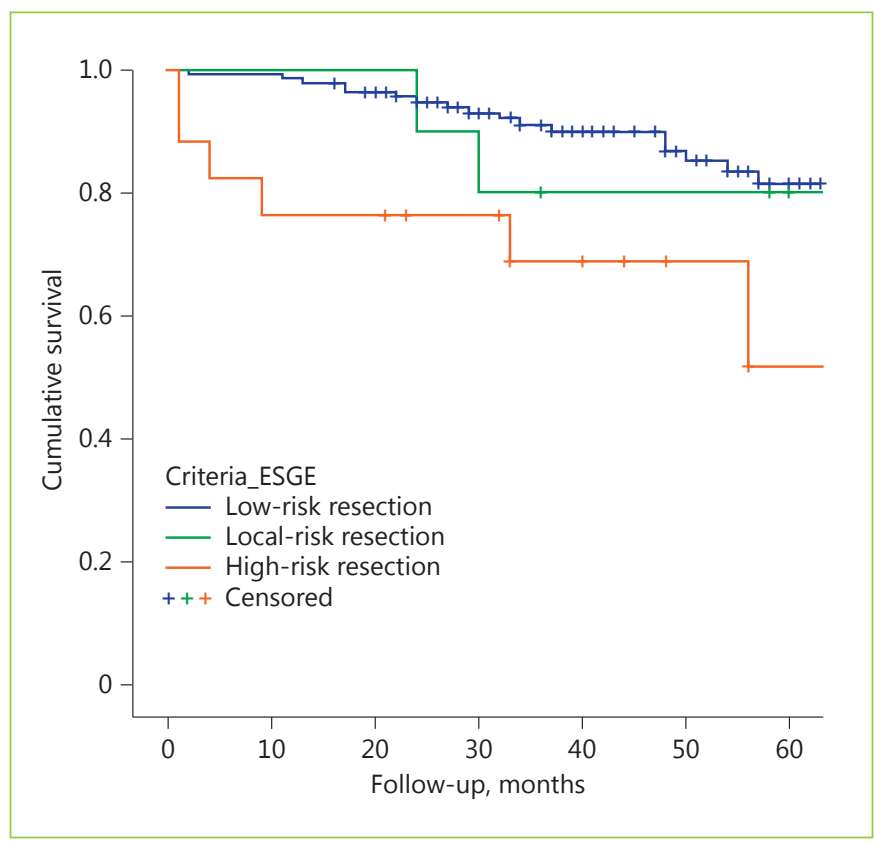

Fig. 3. Survival was not significantly different in patients with lowand local-risk resection; however, high-risk resection was significantly associated with a worse survival.

were significantly associated with a higher metachronous incidence in univariate analysis $(p<0.05)$. However, multivariate analysis identified only age as a significant predictor for metachronous lesion occurrence ( $p=0.042$; $\mathrm{OR}_{10 \text { years }} 1.68,95 \% \mathrm{CI} 1.03-2.74$ ).

\section{Survival}

In the entire cohort, overall survival was 94.5 and $89.5 \%$ at 1 and 3 years, respectively; disease-specific survival was $99.4 \%$, with only 1 patient dying of gastric cancer. The median follow-up time was 40 months.

Survival was significantly higher in patients with curative resection (log-rank $4.538, p=0.033$; Fig. 2 ). In the non-curative resection group, patients submitted to surgery were significantly younger (mean age $66.7 \pm 9.4$ vs. $73.6 \pm 7.5$ in the follow-up group, $p=0.037$ ) and less frequently classified as ASA III/IV (23.1 vs. $31.3 \%, p=0.62$ ). However, survival was not significantly different in the two groups (log-rank 0.009, $p=0.929$; Fig. 2).

Comparing survival according to the ESGE criteria, survival in patients with high-risk resection was significantly worse than in patients with low-risk resection (logrank 7.539, $p=0.006$ ), while no significant differences were found in the survival of patients with low- and localrisk resection (log-rank 0.133, $p=0.715$; Fig. 3 ). 
This study reports the long-term outcomes of gastric ESD in the largest cohort with the longest follow-up in a Western centre in Europe. We previously reported our initial experience with endoscopic mucosal resection and ESD in the treatment of gastric superficial neoplasms and found that ESD was associated with higher complete resection rates and lower recurrence rates, with similar complications [12]. The present study focused only on ESD in a larger cohort of patients with a longer follow-up. We evaluated the risk factors for non-curative resection, and the management and outcome after its occurrence. We found that carcinoma detected in biopsies before resection is an independent predictor of non-curative resection, and that surveillance may be an adequate option in older patients with non-curative resections. Additionally, we found that the incidence of metachronous lesions is significant and that older age is an independent predictor for its development.

Endoscopic resection with ESD is now considered a first-line treatment for early gastric neoplasms in European guidelines. The detection rate of these lesions is increasing, and technical advances facilitate the resection of lesions of increasing size and in difficult localizations.

However, endoscopic resection is non-curative in 80$85 \%$ of the cases $[11,12]$. The long learning curve of ESD and the human and health care resources consumed by endoscopic resection are compelling factors to improve patient selection. Indeed, although it can be argued that endoscopic resection is the best staging for early lesions, it is important to select the patients with the best probability of a successful curative resection in order to make better use of health care resources and to manage patient expectations.

In this study, we identified male sex, tumor size $\geq 20$ $\mathrm{mm}$, a longer procedure time, and older age to be associated with treatment failure, although only carcinoma detected in biopsies before resection was an independent predictor for non-curative resection. The association of older age with non-curative resection is probably explained by selection bias, since the initial patients were typically those with a higher surgical risk and with more advanced lesions. The identification of carcinoma in histological sections before resection as an independent predictor of treatment failure is a novel and interesting finding. Indeed, although we know that histological upgrade frequently occurs when the entire tumor is evaluated in the resection specimen, biopsies reveal lesion features prior to treatment and can help in adequate selection,

Long-Term Outcomes of Gastric ESD which improves the information transmitted to the patient, too. Lesion size $\geq 20 \mathrm{~mm}$ was also associated with non-curative resection, although it was not identified as an independent predictor. Nevertheless, data from other studies suggest that the likelihood of non-curative resection increases with increasing tumor size $[13,14]$. Resection of polypoid lesions was frequently non-curative (23.5\%), although the association was not statistically significant. These findings are in agreement with studies showing a higher probability of submucosal invasion in polypoid neoplastic lesions [8]. Although localization and morphology were not found to influence curability, data from other studies suggest that lesions located in the upper stomach and ulcerated lesions are also associated with non-curative resections [13-15].

The incidence of metachronous lesions was high, occurring in $18.4 \%$ of the patients during follow-up. The incidence rate of 5 lesions/100 patient-years means that, on average, one-fourth of the patients followed up for 5 years will have a metachronous lesion detected. One should expect that younger patients, which have a longer survival time (and thus more time to develop a metachronous lesion), could have a higher incidence of metachronous lesions. However, we found that patients with metachronous lesions are significantly older, and increasing age was identified as a significant predictor for the development of metachronous lesions, which may possibly be explained by the presumably higher prevalence of preneoplastic conditions. Unfortunately, information about preneoplastic conditions could not be retrieved from clinical records, and thus we could not evaluate the influence of preneoplastic conditions on metachronous lesion development. Our findings are in line with those from a recent large retrospective study where age was also associated with metachronous lesions [16]. Intestinal metaplasia and flat/depressed lesions were other factors that increase this risk. Surprisingly, our incidence rate was even higher than that reported in an Asian population (18.4/1,000 person-years) [17]. Our findings suggest that endoscopic surveillance is probably of benefit even 5 years after resection.

Another important issue is how to manage patients after non-curative resection. Even if granting curability is important in the majority of cases, patient age and comorbidities increase surgical risks, and surgery may be overtreatment in certain cases. Using the new risk stratification tool provided by the ESGE guidelines for the first time, we show favourable outcomes in patients with localrisk resections, with only 1 patient experiencing a recurrence that was successfully treated with further endo- 
scopic resection. Survival was also not significantly different in patients with low- and local-risk resections. Additional findings suggest that surveillance may be a more adequate option in certain patients: (1) survival was similar in patients with non-curative resections independent of the treatment choice, although patients followed up were significantly older and more frequently ASA III/ IV, and (2) $75 \%$ of the patients submitted to surgery did not have residual disease in the gastrectomy/lymphadenectomy specimen. However, an Asian study suggested that surgery is associated with a lower recurrence, especially in high-risk cases (incomplete resection in lesions exceeding curative criteria and lesions with lymphovascular invasion) [18]. Another study also suggested a survival benefit with surgery in cases of non-curative resection [19], although it is difficult to make definite conclusions because patients allocated to surveillance are generally older and have more comorbidities. We suggest that in high-risk resections the decision should be individualized, taking age, comorbidities, surgical risk, pathological features (with special attention to lymphovascular invasion), and patient preferences into account.

This study has some limitations. First, data on the influence of preneoplastic conditions and the H. pylori status on metachronous development was not available due to frequently missing data. Second, our cohort is smaller than those from Asian studies, and this study may be underpowered to detect the influence of risk factors such as morphology and localization.

Despite these limitations, this is the largest European cohort and the first European study that tried to identify risk factors for treatment failure and for metachronous lesion development, which is important to improve pa- tient selection and adequate surveillance. Besides, the long follow-up indicates that ESD is associated with a high cancer-free survival and that surveillance may be appropriate in selected patients not strictly meeting criteria for curative therapy. Moreover, the high incidence of metachronous lesions alerts for the need of continuing endoscopic follow-up with special attention to older patients.

In conclusion, ESD is an effective and safe treatment for gastric superficial neoplasms and associated with a high cancer-free survival, although lifelong endoscopic surveillance may be necessary to detect metachronous lesions. Carcinoma detected in biopsies before resection is a significant predictor of treatment failure. Conservative management after non-curative resection is an option in selected patients, especially in local-risk resections.

\section{Statement of Ethics}

Protection of human and animal subjects: the authors declare that the procedures followed were in accordance with the regulations of the relevant clinical research ethics committee and with those of the Code of Ethics of the World Medical Association (Declaration of Helsinki). Confidentiality of data: the authors declare that they have followed the protocols of their work center on the publication of patient data. Right to privacy and informed consent: The authors have obtained the written informed consent of the patients or subjects mentioned in the article. The corresponding author is in possession of this document.

\section{Disclosure Statement}

The authors have no conflicts of interest to declare.

\section{References}

1 Ferlay J, Soerjomataram I, Ervik M, Dikshit R, Eser S, Mathers C, et al: GLOBOCAN 2012 v1.0, Cancer Incidence and Mortality Worldwide: IARC CancerBase No. 11. Lyon, International Agency for Research on Cancer, 2013.

2 Morais S, Ferro A, Bastos A, Castro C, Lunet $\mathrm{N}$, Peleteiro B: Trends in gastric cancer mortality and in the prevalence of Helicobacter pylori infection in Portugal. Eur J Cancer Prev 2016;25:275-281.

3 Pinho I, Santos JV, Dinis-Ribeiro M, Freitas A: Burden of digestive diseases in Portugal: trends in hospitalizations between 2000 and 2010. Eur J Gastroenterol Hepatol 2015;27: 279-289.
4 Dinis-Ribeiro M, Areia M, de Vries AC, Marcos-Pinto R, Monteiro-Soares M, O'Connor A, et al: Management of precancerous conditions and lesions in the stomach (MAPS): guideline from the European Society of Gastrointestinal Endoscopy (ESGE), European Helicobacter Study Group (EHSG), European Society of Pathology (ESP), and the Sociedade Portuguesa de Endoscopia Digestiva (SPED). Endoscopy 2012;44:74-94.

5 Chiu PW, Teoh AY, To KF, Wong SK, Liu SY, Lam CC, et al: Endoscopic submucosal dissection (ESD) compared with gastrectomy for treatment of early gastric neoplasia: a retrospective cohort study. Surg Endosc 2012;26: 3584-3591.
6 Kim DY, Hong SJ, Cho GS, Jeong GA, Kim HK, Han JP, et al: Long-term efficacy of endoscopic submucosal dissection compared with surgery for early gastric cancer: a retrospective cohort study. Gut Liver 2014;8:519-525.

7 Choi JH, Kim ES, Lee YJ, Cho KB, Park KS, Jang BK, et al: Comparison of quality of life and worry of cancer recurrence between endoscopic and surgical treatment for early gastric cancer. Gastrointest Endosc 2015;82:299307.

8 The Paris endoscopic classification of superficial neoplastic lesions: esophagus, stomach, and colon: November 30 to December 1, 2002. Gastrointest Endosc 2003;58:S3-S43. 
9 Schlemper RJ, Riddell RH, Kato Y, Borchard F, Cooper HS, Dawsey SM, et al: The Vienna classification of gastrointestinal epithelial neoplasia. Gut 2000;47:251-255.

10 Japanese Gastric Cancer Association: Japanese gastric cancer treatment guidelines 2010 (ver. 3). Gastric Cancer 2011;14:113-123.

11 Pimentel-Nunes P, Dinis-Ribeiro M, Ponchon T, Repici A, Vieth M, De Ceglie A, et al: Endoscopic submucosal dissection: European Society of Gastrointestinal Endoscopy (ESGE) Guideline. Endoscopy 2015;47:829854.

12 Pimentel-Nunes P, Mourao F, Veloso N, Afonso LP, Jacome M, Moreira-Dias L, et al: Long-term follow-up after endoscopic resection of gastric superficial neoplastic lesions in Portugal. Endoscopy 2014;46:933-940.
13 Toyokawa T, Inaba T, Omote S, Okamoto A, Miyasaka R, Watanabe $\mathrm{K}$, et al: Risk factors for non-curative resection of early gastric neoplasms with endoscopic submucosal dissection: analysis of 1,123 lesions. Exp Ther Med 2015;9:1209-1214.

14 Ohnita K, Isomoto H, Yamaguchi N, Fukuda E, Nakamura T, Nishiyama H, et al: Factors related to the curability of early gastric cancer with endoscopic submucosal dissection. Surg Endosc 2009;23:2713-2719.

15 Goto A, Nishikawa J, Okamoto T, Hamabe K, Nishimura J, Nakamura M, et al: Outcomes of endoscopic submucosal dissection for early gastric cancer and factors associated with incomplete resection. Hepatogastroenterology 2013;60:46-53

16 Hahn KY, Park JC, Kim EH, Shin S, Park CH, Chung $\mathrm{H}$, et al: Incidence and impact of scheduled endoscopic surveillance on recurrence after curative endoscopic resection for early gastric cancer. Gastrointest Endosc 2016;84:628.e1-638.e1.
17 Yoon SB, Park JM, Lim CH, Kim JS, Cho YK Lee BI, et al: Incidence of gastric cancer after endoscopic resection of gastric adenoma. Gastrointest Endosc 2016;83:1176-1183.

18 Han JP, Hong SJ, Kim HK, Lee YN, Lee TH, Ko BM, et al: Risk stratification and management of non-curative resection after endoscopic submucosal dissection for early gastric cancer. Surg Endosc 2016;30:184-189.

19 Kusano C, Iwasaki M, Kaltenbach T, Conlin A, Oda I, Gotoda T: Should elderly patients undergo additional surgery after non-curative endoscopic resection for early gastric cancer? Long-term comparative outcomes. Am J Gastroenterol 2011;106:1064-1069. 